\title{
Three-dimensional assessment of teeth first-, second- and third-order position in Caucasian and African subjects with ideal occlusion
}

\author{
Luca Lombardo*, Alessandro Perri, Angela Arreghini, Michele Latini and Giuseppe Siciliani
}

\begin{abstract}
Background: The aim of this study was to provide an updated version of Andrews' seminal study by exploiting 3D software to analyse the tip, torque and in-out values of two groups of different racial and ethnic background.

Methods: The analysis was conducted on one Caucasian group (30 individuals) and one of African origin (29). All subjects were adult, in normal occlusion and had no previous history of orthodontic treatment. Rhinoceros ${ }^{\text {TM }} 3 \mathrm{D}$ modelling software was used to identify anatomical reference points, planes and axes and to make the appropriate measurements.

Results: Compared to Andrews' measurements, we found more positive coronal tip values in both African and Caucasian subjects, while the torque values we measured tended to be less negative in the posterior sectors than those reported by Andrews. We measured greater tip values in the lower jaw of Caucasian with respect to African subjects, particularly in the middle sectors.

Conclusions: Race and ethnicity have a strong influence on values of tip, torque and in-out. This is translated as a more positive tip in Caucasian subjects and a more positive torque in those of African descent (greater proclination of the incisors). Finally, with respect to the values reported by Andrews, we found a tendency to more positive mean tip (except for at the upper second molars and lower incisors) and less negative torque in the posterior sectors.
\end{abstract}

Keywords: Tip; Torque; In-out; Straight-wire prescription; Andrews

\section{Background}

Andrews was the first to put forward the hypothesis that the ideal occlusion of untreated patients could serve as the target of orthodontic treatment [1]. However, despite Andrews' undeniable influence on orthodontics as we know it today, several authors [1-6] have identified sources of bias in this seminal study, in both the method Andrews adopted for making his measurements-ascribable to the instruments he used-and the sample he selectedNorth American subjects of Caucasian origin. Nevertheless, only Sebata [2], Watanabe [3], Currim [4] and Doodamani [5] have since replicated Andrews' study using different samples (Japanese in the first two, Indians in the latter two) and a modified method. As could be expected from the different approaches used and samples

\footnotetext{
* Correspondence: lulombardo@tiscali.it

Department of Orthodontics, University of Ferrara, Via montebello, 31, Ferrara 44100, Italy
}

considered in these investigations, all four produced results that were significantly different from those of Andrews.

In spite of the many advances in orthodontics since Andrews' proposed his pre-programmed appliance, the majority of devices on the market still feature prescriptions based on his measurements. This means that, generally speaking, not enough attention is paid to the position of the roots. In reality, there is a strong correlation between the tip and torque and the tooth root position, as there are variations in coronal morphology, incongruencies between the inclination of the roots and the crown, and a disproportion between the height of the crown and the length of the root of the same tooth [7].

That being said, measurement of the angulation and inclination of the roots relies on 3D imaging, which has only been available in recent years following the development of such diagnostic tool technology. In this regard, the 
Table 1 Inclusion criteria

Adult age (not less than 18 years)

Regular arch form with little or no crowding

No bridges or implants

No gingival recession

No ectopic teeth

At least four of Andrews' six keys with bilateral molar and canine class I occlusion always present

Overbite and overjet within normal limits $2 \mathrm{~mm} \pm 1 \mathrm{~mm}$
No previous orthodontic treatment

Complete dentition to second molars

Centred midlines

No joint or muscle pathologies

No supernumerary teeth or tooth agenesis

Presence of minimal diastems and/or small premolar rotation or little irregularity (Little's index less than 3) at incisors in some individuals

No anterior or posterior cross-bite

No markedly visible intra-oral or extra-oral symmetry

study by Tong [8] was a real innovation; its aim was to analyse the tip and torque of the teeth in patients in normal, or nearly normal, occlusion by means of CBCT. The only flaw in that study was the fact that it was carried out on a small sample of single ethnicity (13 Caucasians).

Huanca Ghislanzoni et al. [9] have validated a method for the analysis of 3D virtual casts, which allow to identify the values of the first, second and third order of teeth with great intra- and inter-operator reproducibility. This confirms the potential of new technologies in obtaining reliable data for clinical diagnosis and the tooth position.

As mentioned, to date, no researcher has attempted to replicate Andrews' work exploiting the potential of today's technology, which provides a far greater degree of accuracy and reproducibility than can be obtained by the manual methods available in his time. Hence, we set out to compare the values manually measured by Andrews with those, based on the same anatomical reference points and planes, obtained using digital technology to determine whether Andrews' values are still relevant or whether significant differences indicate that digital measurements provide us with better reference values. We also extended the study to two ethnic groups.

\section{Methods}

\section{Sample selection}

The study was conducted on a sample made up of two groups of adults in ideal occlusion with no previous history of orthodontic treatment, one of Caucasian and one of African origin. Thirty Caucasian subjects (14 males and 16 females) were recruited from among patients presenting for general dentistry procedures or routine check-up at various private practices in Italy, and 29 African subjects (14 males and 15 females) were recruited from among the students of the Eduardo Mondlane University in Inhambane, Mozambique. Subject selection was performed according to the inclusion criteria noted in Table 1.

Precision impressions of the dental arcades of each patient were taken using the dual-phase putty and light body (Elite HD+ Fast Set, Zhermack, Rovigo, Italy) technique. Bite registrations of each patient's dentition were taken in maximum intercuspidation. Silicone was chosen as the impression material due to its precision and dimensional stability [10]. Each subject's impressions were placed in an orthodontic 3D scanner (3Shape D700/710, Copenhagen, Denmark) to obtain virtual 3D renderings in stereolithography (STL) format (Fig. 1). The anatomical reference points, axes and planes on these renderings were marked using Rhinoceros ${ }^{\mathrm{Tm}} 4.0$ 3D modelling software (Robert McNeel \& Associates, Seattle, USA), which was also used to make the measurements detailed below.

\section{Measurements taken}

Tip and torque: two operators performed measurements. Both operators used Rhinoceros ${ }^{\mathrm{Tm}}$ software to make the measurements, which were based on the anatomical reference points described by Andrews. The occlusal plane was identified on each 3D rendering and used as a plane of reference. This plane, described by Rhinoceros as the "C-plane", was made to pass through three anatomical points: the inter-incisal point and the halfway points on

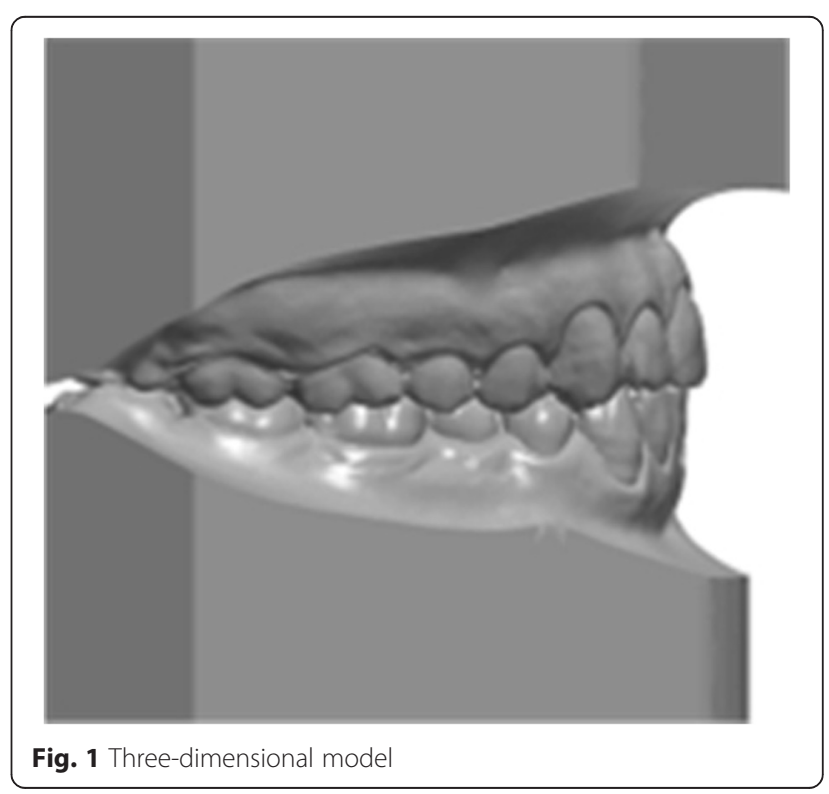




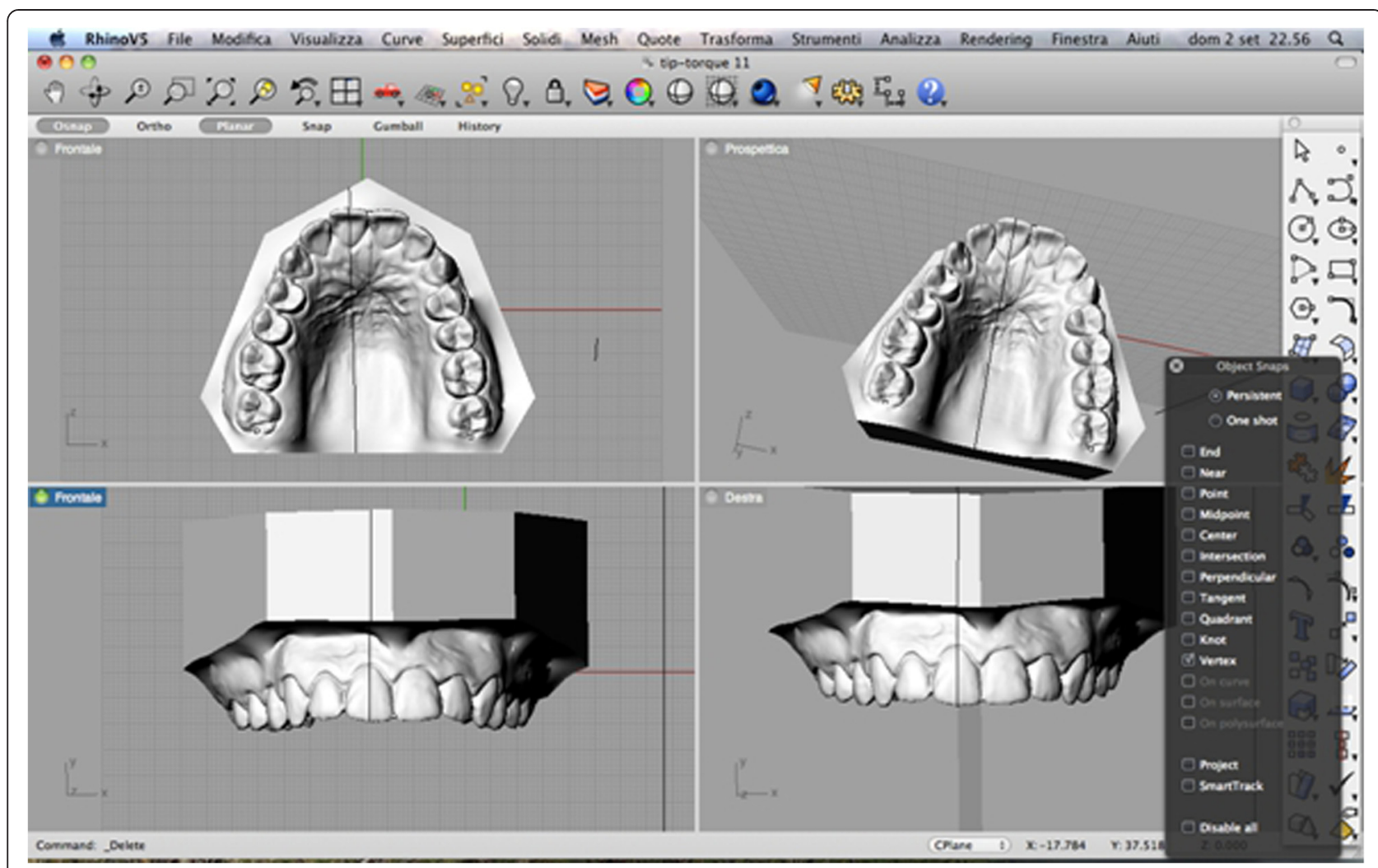

Fig. 2 Measuring the FACC

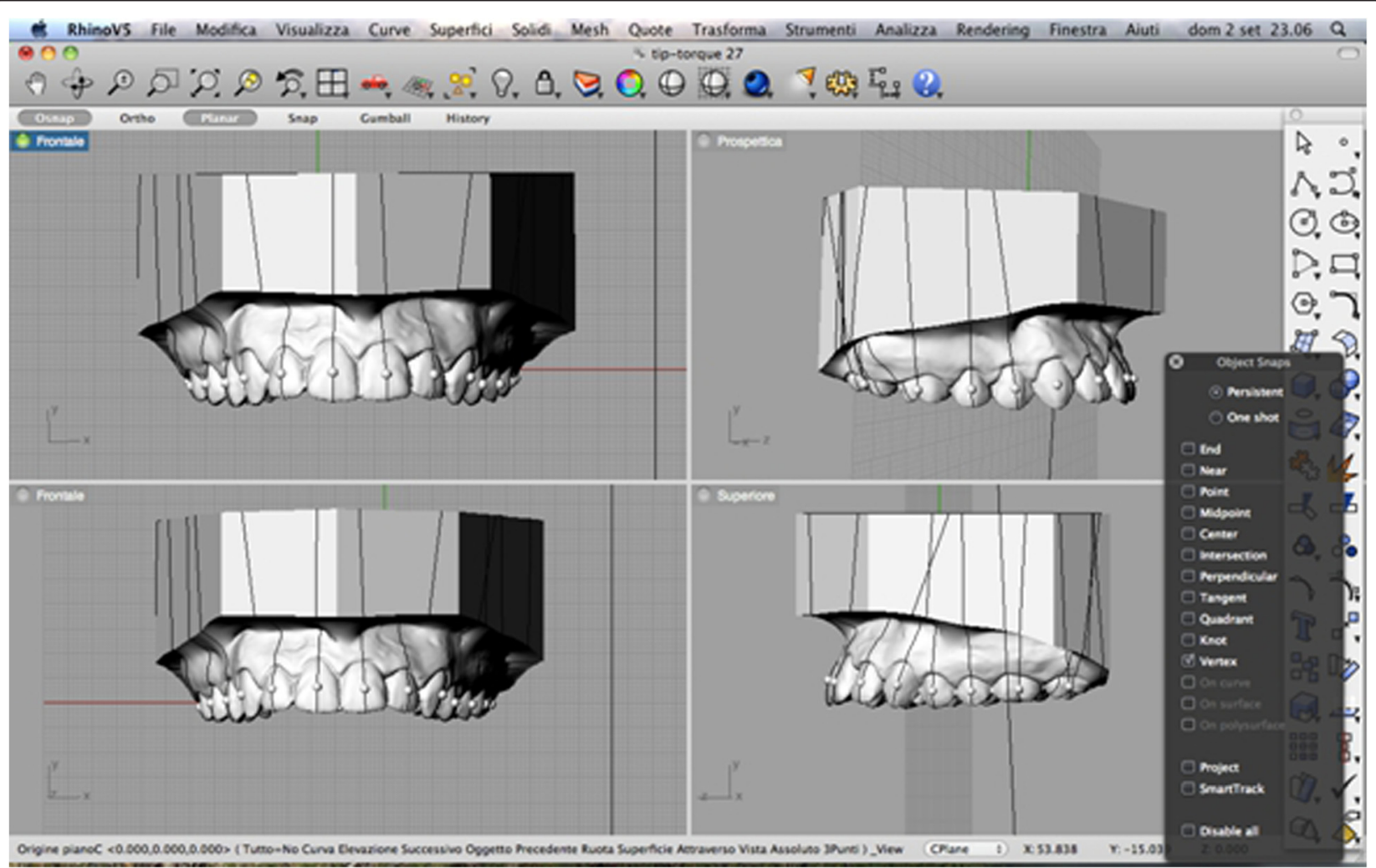

Fig. 3 Creation of virtual spheres around FA points 


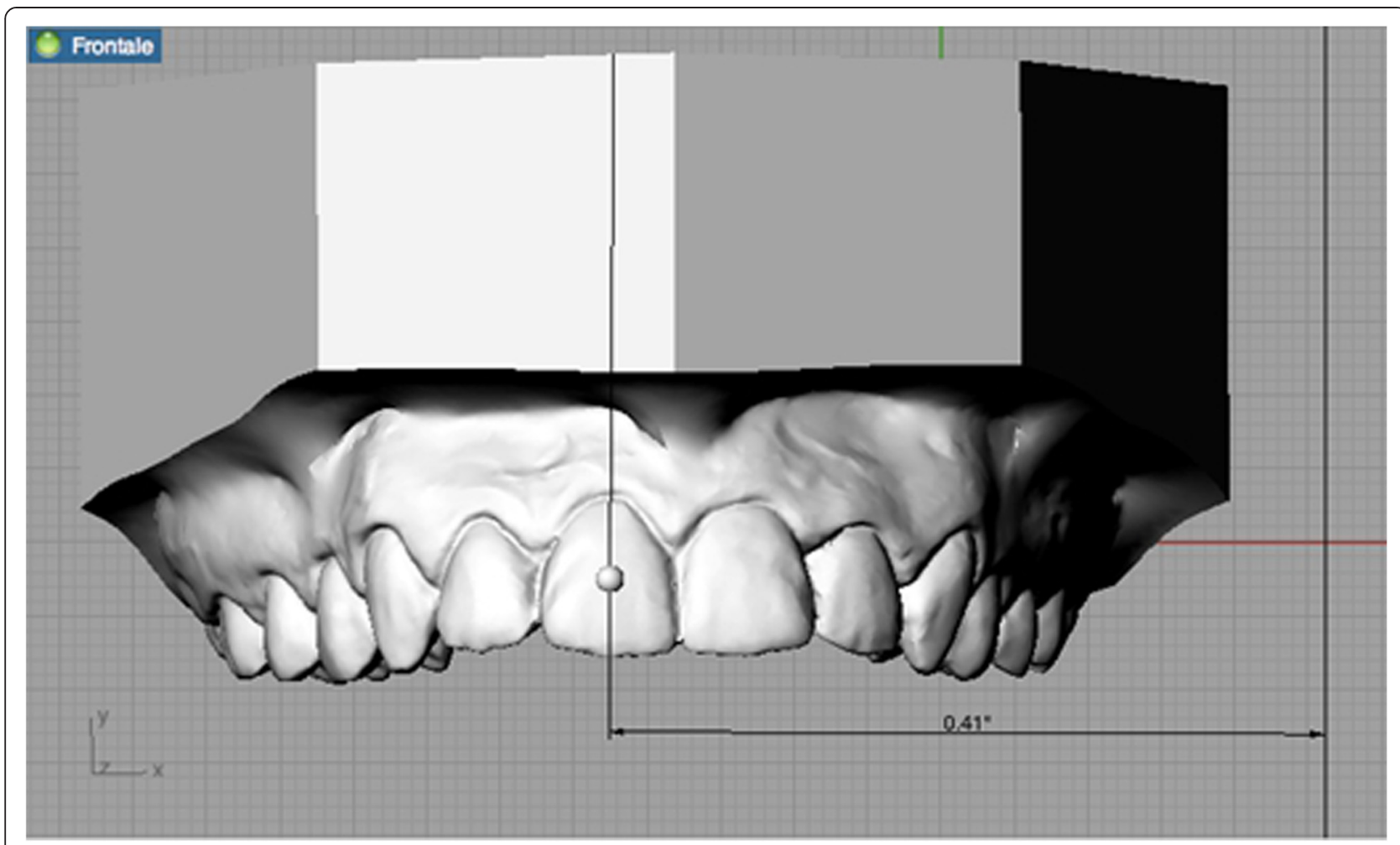

Fig. 4 Calculating the upper central incisor tip

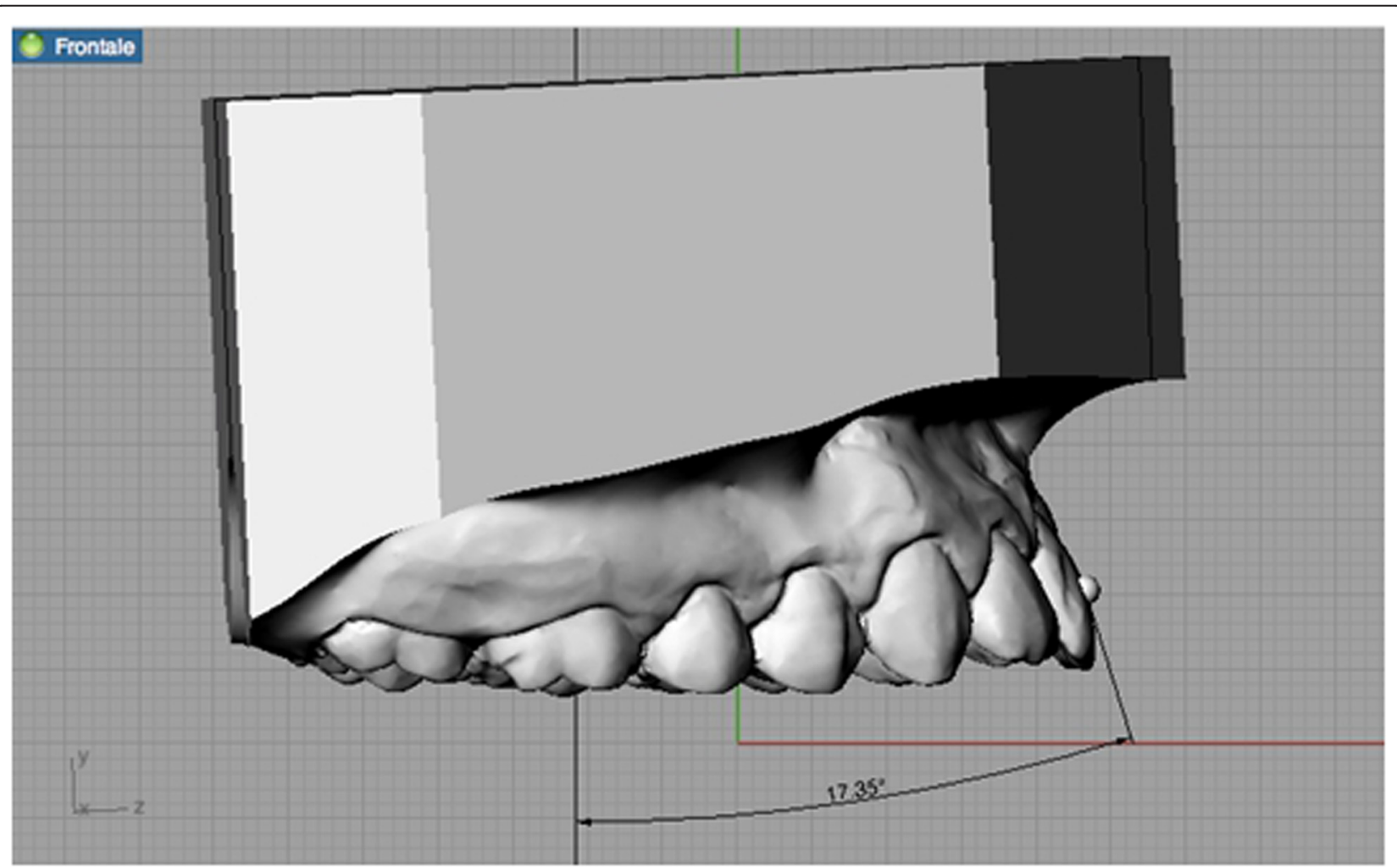

Fig. 5 Calculating the upper central incisor torque 


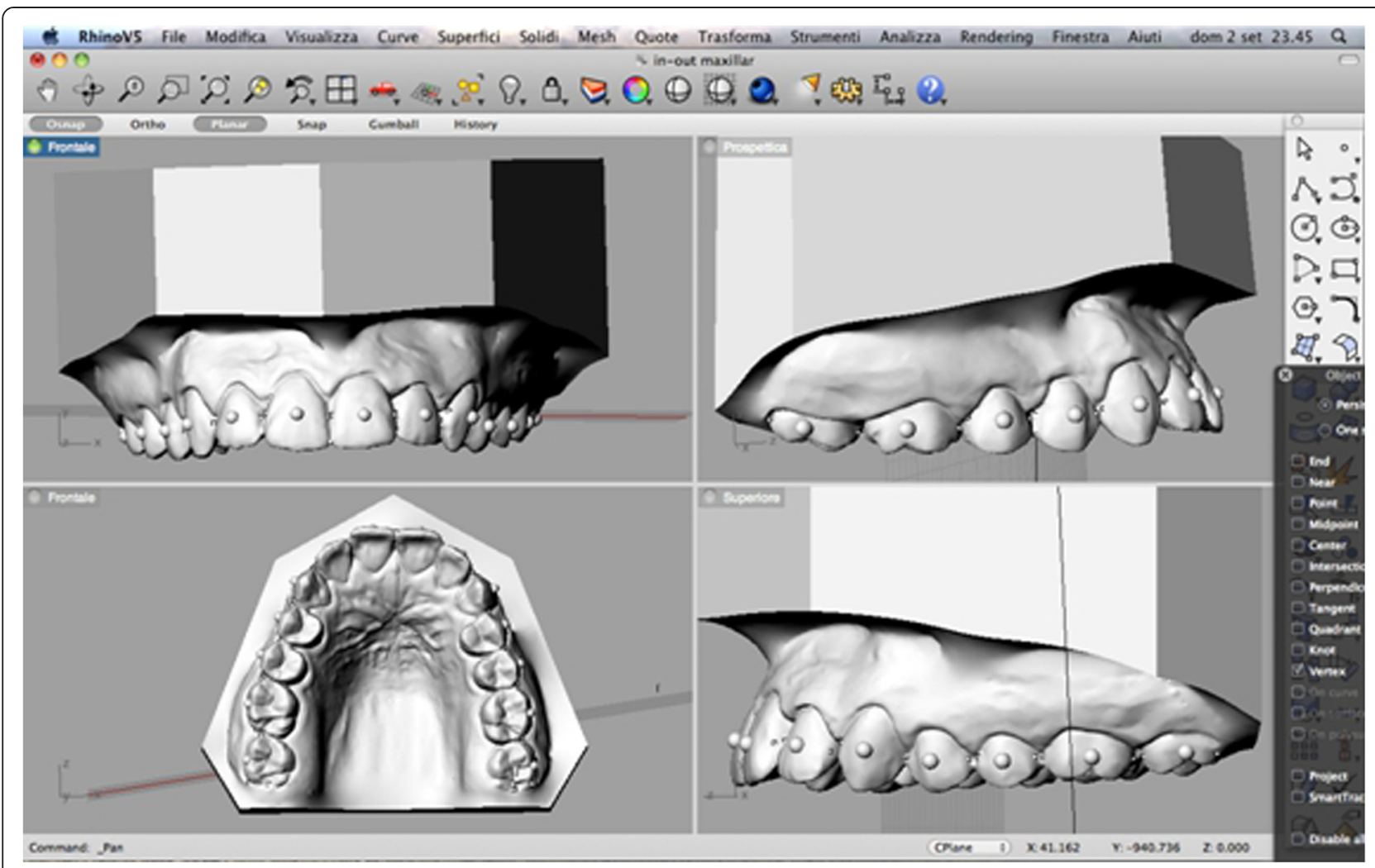

Fig. 6 Determining contact points

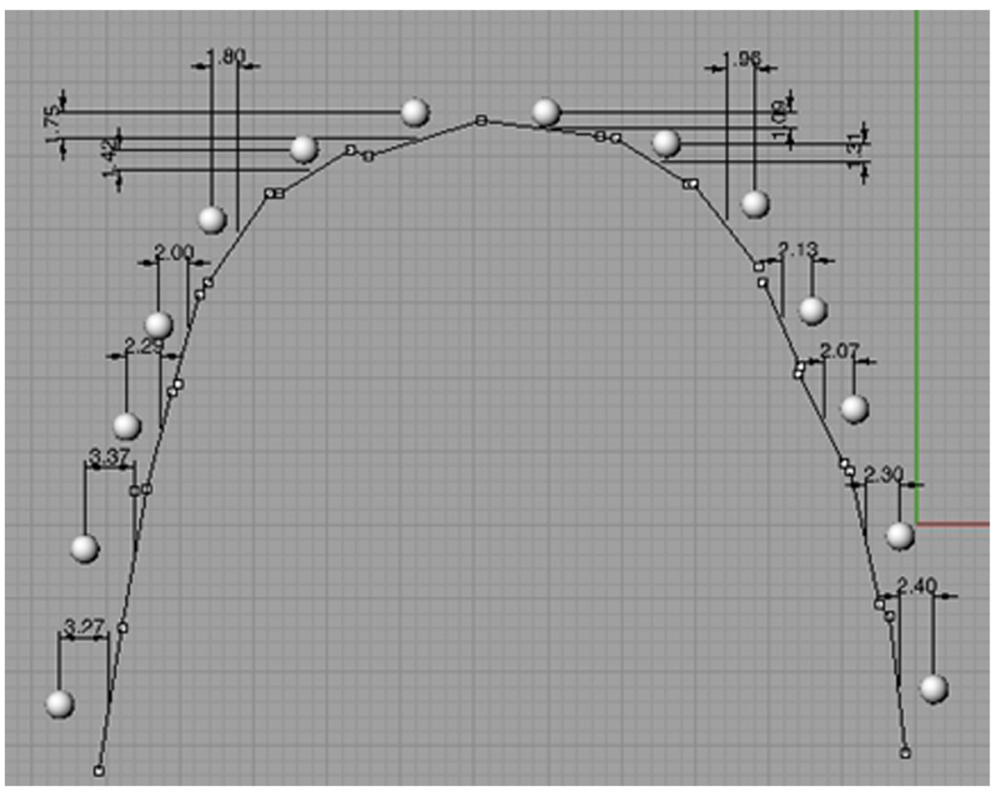

Fig. 7 Calculating the in-out 
Table 2 Comparison of tip values measured for the two groups

\begin{tabular}{|c|c|c|c|c|c|c|c|c|}
\hline \multicolumn{4}{|c|}{ Africans-tip } & \multicolumn{3}{|c|}{ Caucasians-tip } & \multicolumn{2}{|c|}{ Comparison } \\
\hline & $n$ & Mean & Standard deviation & $n$ & Mean & Standard deviation & $t$ test & $p$ level \\
\hline TIP U7 & 58 & -3.06 & 6.78 & 60 & -3.88 & 10.60 & 0.51 & ns \\
\hline TIP U6 & 58 & 9.48 & 3.53 & 60 & 10.26 & 5.54 & -0.98 & ns \\
\hline TIP U5 & 58 & 5.96 & 5.84 & 60 & 9.64 & 4.16 & -3.93 & $<0.001$ \\
\hline TIP U4 & 58 & 3.29 & 4.45 & 60 & 7.67 & 4.28 & -5.45 & $<0.001$ \\
\hline TIP U3 & 58 & 8.23 & 5.20 & 60 & 9.96 & 4.81 & -1.87 & ns \\
\hline TIP U2 & 58 & 9.23 & 3.87 & 60 & 9.99 & 3.69 & -1.10 & ns \\
\hline TIP U1 & 58 & 3.68 & 3.55 & 60 & 4.53 & 2.84 & -1.44 & ns \\
\hline TIP L7 & 58 & 12.65 & 5.83 & 60 & 14.20 & 6.47 & -1.37 & ns \\
\hline TIP L6 & 58 & 6.30 & 5.36 & 60 & 10.99 & 2.78 & -5.95 & $<0.001$ \\
\hline TIP L5 & 58 & 3.60 & 4.02 & 60 & 6.90 & 3.09 & -4.99 & $<0.001$ \\
\hline TIP L4 & 58 & 2.95 & 3.89 & 60 & 6.06 & 3.36 & -4.63 & $<0.001$ \\
\hline TIP L3 & 58 & 3.478 & 4.850 & 60 & 5.91 & 3.98 & -2.98 & 0.004 \\
\hline TIP L2 & 58 & -0.26 & 3.01 & 60 & 0.14 & 4.46 & -0.57 & ns \\
\hline TIP L1 & 58 & -1.13 & 3.30 & 60 & 0.00 & 4.46 & -1.57 & ns \\
\hline
\end{tabular}

ns not significant.

the distal marginal crest of each second molar. After the occlusal plane was aligned visually, the line perpendicular to it was traced. The facial axis of each tooth crown (FACC) was marked using the "section" tool, in all cases making sure that the $\mathrm{C}$-plane was aligned correctly. To make the facial axis (FA) point visible, this was placed in the centre of a virtual 1-mm sphere whose centre lay on the previously traced axis (Figs. 2 and 3). Once these anatomical reference points had been marked on the renderings, the tip and torque of each tooth were measured. The tip was taken as the angle between the FACC and the line perpendicular to the occlusal plane, using the "Evaluate/angle" function (Fig. 4). To calculate the torque, a tangent line was drawn perpendicular to the surface of each tooth, passing through the FA point (i.e. the centre of the virtual sphere) on a mesiodistal view of each tooth (therefore positioned at $90^{\circ}$ with respect to the FACC), the angle between this line and the occlusal reference plane was calculated (Fig. 5).

Table 3 Comparison of torque values measured for the two groups

\begin{tabular}{|c|c|c|c|c|c|c|c|c|}
\hline \multicolumn{4}{|c|}{ Africans-torque } & \multicolumn{3}{|c|}{ Caucasians-torque } & \multicolumn{2}{|c|}{ Comparison } \\
\hline & $n$ & Mean & Standard deviation & $n$ & Mean & Standard deviation & $t$ test & $p$ level \\
\hline TORQUE U7 & 58 & -12.79 & 10.11 & 60 & -5.50 & 12.23 & -3.54 & $<0.001$ \\
\hline TORQUE U6 & 58 & -10.98 & 9.75 & 60 & -6.26 & 10.24 & -2.56 & 0.013 \\
\hline TORQUE U5 & 58 & -4.00 & 8.43 & 60 & -3.54 & 6.42 & -0.33 & ns \\
\hline TORQUE U4 & 58 & -4.49 & 8.38 & 60 & -5.35 & 5.64 & 0.65 & ns \\
\hline TORQUE U3 & 58 & -2.03 & 7.95 & 60 & -3.35 & 7.15 & 0.95 & ns \\
\hline TORQUE U2 & 58 & 7.41 & 8.14 & 60 & 6.23 & 6.31 & 0.88 & ns \\
\hline TORQUE U1 & 58 & 11.41 & 6.28 & 60 & 7.41 & 6.19 & 3.49 & $<0.001$ \\
\hline TORQUE L7 & 58 & -32.51 & 10.93 & 60 & -33.26 & 11.69 & 0.36 & ns \\
\hline TORQUE L6 & 58 & -23.50 & 9.57 & 60 & -29.24 & 9.29 & 3.31 & 0.003 \\
\hline TORQUE L5 & 58 & -11.39 & 8.52 & 60 & -17.43 & 7.98 & 3.97 & $<0.001$ \\
\hline TORQUE L4 & 58 & -9.23 & 7.02 & 60 & -14.96 & 7.69 & 4.23 & $<0.001$ \\
\hline TORQUE L3 & 58 & -1.95 & 7.49 & 60 & -9.01 & 5.74 & 5.73 & $<0.001$ \\
\hline TORQUE L2 & 58 & 5.50 & 8.26 & 60 & -1.36 & 6.89 & 4.90 & $<0.001$ \\
\hline TORQUE L1 & 58 & 9.68 & 9.18 & 60 & 2.19 & 7.11 & 4.94 & $<0.001$ \\
\hline
\end{tabular}

ns not significant. 


\section{a AFRICANS a CAUCASIAN}

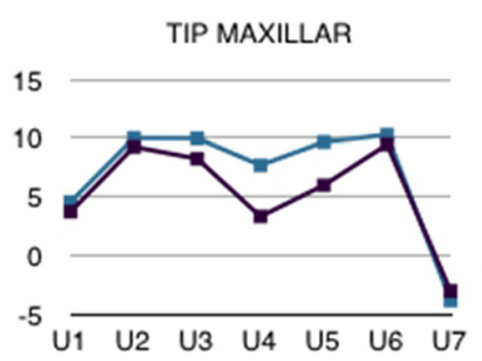

\section{- AFRICANS a CAUCASIAN}

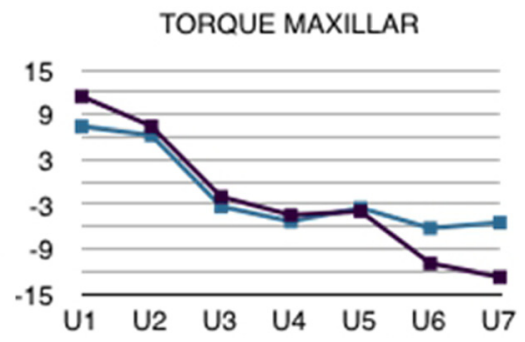

Fig. 8 Comparing African and Caucasian tip and torque values for the upper jaw

In-out: a plane parallel to the occlusal plane, passing through the FA point of each tooth, was identified, and the mesial, the distal and the most vestibular point of every tooth was selected (Fig. 6). These points were joined together by a line whose perpendicular distance from the FA point (i.e. the centre of the virtual sphere) was taken as the in-out value of that crown. These values were calculated using the "Evaluate/Distance" ! ?/"Evaluate/Length" ! ?' software tool (Fig. 7).

\section{Statistical analysis}

The mean, standard deviation and standard error of each value obtained above were calculated. The Shapiro-Wilk test was performed to assess the normal distribution of the studied samples. Student's $t$ test for independent samples (significance level $p<0.05$ ) was used to compare the group mean values for every tooth. To verify the repeatability of the measurements performed, 10 renderings of the upper arcade and 10 of the lower were selected at random from each ethnic sample. The measurements were then repeated by the other operator, and the second set of measurements was compared with the first by means of measurement systems analysis (MSA) conducted using the $t$ test for paired data.

\section{Results}

\section{African sample}

The measurements taken of the upper jaw highlight positive tip values for all the teeth except for the second molars (Table 2). The tip values in the lower jaw tended to be more positive in an anteroposterior direction (Table 2), whereas the torque on both the upper and lower teeth tended to get more negative in an anteroposterior direction (Table 3); only the central and lateral incisors displayed positive torque.

\section{Caucasian sample}

With the exception of the second molar, tip values in the upper jaw were all positive, displaying a tendency to decrease from the anterior to the posterior sectors (Table 2). The lower tip values were all positive, but tended to increase in an anteroposterior direction (Table 2). As for torque, in the upper jaw, this showed a tendency to increase in negativity in an anteroposterior direction, being positive at the incisors and negative in the canines, premolars and molars (Table 3). In the lower jaw, increasingly negative torque values were measured in an anteroposterior direction. Only the central incisors had a positive torque while the most negative torque was seen at the second molars (Table 3).

\section{a AFRICANS a CAUCASIAN}

TIP MANDIBULAR

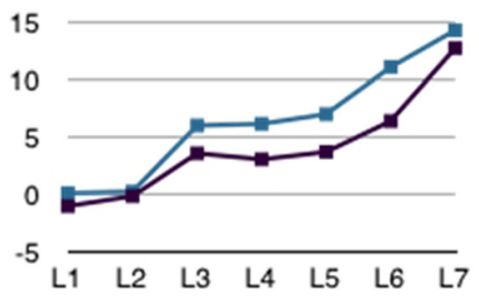

\section{a AFRICANS a CAUCASIAN}

TORQUE MANDIBULAR

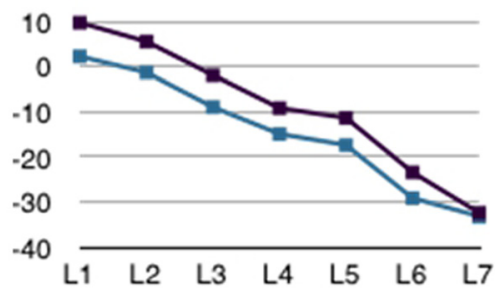

Fig. 9 Comparing African and Caucasian tip and torque values for the lower jaw 
Table 4 Comparison of our African tip values with those measured by Andrews

\begin{tabular}{|c|c|c|c|c|c|c|c|c|}
\hline \multicolumn{4}{|c|}{ Africans-tip } & \multicolumn{3}{|c|}{ Andrews' values } & \multicolumn{2}{|c|}{ Comparison } \\
\hline & $n$ & Mean & Standard deviation & $n$ & Mean & Standard deviation & $t$ test & $p$ level \\
\hline TIP U7 & 58 & -3.06 & 6.78 & 240 & .39 & 5.69 & -3.58 & $<0.001$ \\
\hline TIP U6 & 58 & 9.43 & 3.53 & 240 & 5.73 & 1.90 & 7.71 & $<0.001$ \\
\hline TIP U5 & 58 & 5.96 & 5.84 & 240 & 2.82 & 1.52 & 4.07 & $<0.001$ \\
\hline TIP U4 & 58 & 3.29 & 4.45 & 240 & 2.65 & 1.69 & 1.07 & ns \\
\hline TIP U3 & 58 & 8.23 & 5.20 & 240 & 8.40 & 2.97 & -.24 & ns \\
\hline TIP U2 & 58 & 9.23 & 3.87 & 240 & 8.04 & 2.80 & 2.20 & 0.031 \\
\hline TIP U1 & 58 & 3.68 & 3.55 & 240 & 3.59 & 1.65 & .18 & ns \\
\hline TIP L7 & 58 & 12.65 & 5.83 & 240 & 2.94 & 2.05 & 12.50 & $<0.001$ \\
\hline TIP L6 & 58 & 6.30 & 5.36 & 240 & 2.03 & 1.14 & 6.03 & $<0.001$ \\
\hline TIP L5 & 58 & 3.60 & 4.02 & 240 & 1.54 & 1.35 & 3.84 & $<0.001$ \\
\hline TIP L4 & 58 & 2.95 & 3.89 & 240 & 1.28 & 1.90 & 3.19 & 0.002 \\
\hline TIP L3 & 58 & 3.478 & 4.850 & 240 & 2.48 & 3.28 & 1.49 & ns \\
\hline TIP L2 & 58 & -.26 & 3.01 & 240 & .38 & 1.47 & -1.57 & ns \\
\hline TIP L1 & 58 & -1.13 & 3.30 & 240 & .53 & 1.29 & -3.77 & $<0.001$ \\
\hline
\end{tabular}

ns not significant.

\section{Measurement system analysis}

From the analysis of the measurement method, in results that there are no statistically significant differences (significance (two-tailed) <0.05) between the values of tip and torque measured by the two operators, both in the Caucasian and the African groups.

\section{Comparison of tip and torque of African and Caucasian groups}

A comparison of the mean tip and torque values obtained for each ethnic sample was performed using Student's $t$ test for independent samples. This showed that, in terms of tip values in the upper teeth, there were only significant differences between the two groups at the premolars, whose mean tip in the Caucasian samples was roughly $4^{\circ}$ more positive than that in the African group. In the lower jaw, comparable values were only found at the incisors, whereas the tip at the canines, premolars and molars was significantly more positive in the Caucasian sample, at $2.5^{\circ}, 3^{\circ}$ and $4^{\circ}$ greater, respectively (Table 2).

Statistically significant differences were also found in the torque values measured for the upper arch, this time at the central incisors and both sets of molars. In each case, absolute torque values were greater in the African subjects, with a torque $4^{\circ}$ more positive at the central incisors and roughly $5^{\circ}$ and $7^{\circ}$, respectively, at the first and second molars (Table 3). Among the lower teeth, only the second molar torque of the two groups was comparable; all the other teeth displayed more positive torque in the African group, reaching statistical significance in the canines, premolars and first molars. In particular, the
Table 5 Comparison of our Caucasian tip values with those measured by Andrews

\begin{tabular}{|c|c|c|c|c|c|c|c|c|}
\hline \multicolumn{4}{|c|}{ Caucasians_tip } & \multicolumn{3}{|c|}{ Andrews' values } & \multicolumn{2}{|c|}{ Comparison } \\
\hline & $n$ & Mean & $\begin{array}{l}\text { Standard } \\
\text { deviation }\end{array}$ & $n$ & Mean & $\begin{array}{l}\text { Standard } \\
\text { deviation }\end{array}$ & $t$ test & $p$ leve \\
\hline $\begin{array}{l}\text { TIP } \\
\text { U7 }\end{array}$ & 60 & -3.88 & 10.60 & 240 & .39 & 5.69 & -3.02 & 0.004 \\
\hline $\begin{array}{l}\text { TIP } \\
\text { U6 }\end{array}$ & 60 & 10.26 & 5.54 & 240 & 5.73 & 1.90 & 6.24 & $<0.001$ \\
\hline $\begin{array}{l}\text { TIP } \\
\text { U5 }\end{array}$ & 60 & 9.64 & 4.16 & 240 & 2.82 & 1.52 & 12.49 & $<0.001$ \\
\hline $\begin{array}{l}\text { TIP } \\
\text { U4 }\end{array}$ & 60 & 7.67 & 4.28 & 240 & 2.65 & 1.69 & 8.91 & $<0.001$ \\
\hline $\begin{array}{l}\text { TIP } \\
\text { U3 }\end{array}$ & 60 & 9.96 & 4.81 & 240 & 8.40 & 2.97 & 2.40 & 0.019 \\
\hline $\begin{array}{l}\text { TIP } \\
\text { U2 }\end{array}$ & 60 & 9.99 & 3.69 & 240 & 8.04 & 2.80 & 3.83 & $<0.001$ \\
\hline $\begin{array}{l}\text { TIP } \\
\text { U1 }\end{array}$ & 60 & 4.53 & 2.84 & 240 & 3.59 & 1.65 & 2.46 & 0.017 \\
\hline $\begin{array}{l}\text { TIP } \\
\text { L7 }\end{array}$ & 60 & 14.20 & 6.47 & 240 & 2.94 & 2.05 & 13.32 & $<0.001$ \\
\hline $\begin{array}{l}\text { TIP } \\
\text { L6 }\end{array}$ & 60 & 10.99 & 2.78 & 240 & 2.03 & 1.14 & 24.47 & $<0.001$ \\
\hline $\begin{array}{l}\text { TIP } \\
\text { L5 }\end{array}$ & 60 & 6.90 & 3.09 & 240 & 1.54 & 1.35 & 13.12 & $<0.001$ \\
\hline $\begin{array}{l}\text { TIP } \\
\text { L4 }\end{array}$ & 60 & 6.06 & 3.36 & 240 & 1.28 & 1.90 & 10.60 & $<0.001$ \\
\hline $\begin{array}{l}\text { TIP } \\
\text { L3 }\end{array}$ & 60 & 5.913 & 3.980 & 240 & 2.48 & 3.28 & 6.18 & $<0.001$ \\
\hline $\begin{array}{l}\text { TIP } \\
\text { L2 }\end{array}$ & 60 & .14 & 4.46 & 240 & .38 & 1.47 & -.41 & ns \\
\hline $\begin{array}{l}\text { TIP } \\
\text { L1 }\end{array}$ & 60 & .00 & 4.46 & 240 & .53 & 1.29 & -.90 & ns \\
\hline
\end{tabular}

ns not significant. 
Table 6 Comparison of our African torque values with those measured by Andrews

\begin{tabular}{|c|c|c|c|c|c|c|c|c|}
\hline \multicolumn{4}{|c|}{ Africans-torque } & \multicolumn{3}{|c|}{ Andrews' values } & \multicolumn{2}{|c|}{ Comparison } \\
\hline & $n$ & Mean & Standard deviation & $n$ & Mean & Standard deviation & $t$ test & $p$ level \\
\hline TORQUE U7 & 58 & -12.79 & 10.11 & 240 & -8.10 & 5.63 & -3.41 & 0.001 \\
\hline TORQUE U6 & 58 & -10.98 & 9.75 & 240 & -11.53 & 3.91 & .42 & ns \\
\hline TORQUE U5 & 58 & -4.00 & 8.43 & 240 & -8.78 & 4.13 & 4.20 & $<0.001$ \\
\hline TORQUE U4 & 58 & -4.49 & 8.38 & 240 & -8.47 & 4.02 & 3.52 & $<0.001$ \\
\hline TORQUE U3 & 58 & -2.03 & 7.95 & 240 & -7.25 & 4.21 & 4.84 & $<0.001$ \\
\hline TORQUE U2 & 58 & 7.41 & 8.14 & 240 & 4.42 & 4.38 & 2.70 & 0.009 \\
\hline TORQUE U1 & 58 & 11.41 & 6.28 & 240 & 6.11 & 3.97 & 6.14 & $<0.001$ \\
\hline TORQUE L7 & 58 & -32.51 & 10.93 & 240 & -36.03 & 6.57 & 2.35 & 0.030 \\
\hline TORQUE L6 & 58 & -23.50 & 9.57 & 240 & -30.67 & 5.90 & 5.46 & $<0.001$ \\
\hline TORQUE L5 & 58 & -11.39 & 8.52 & 240 & -23.63 & 5.58 & 10.41 & $<0.001$ \\
\hline TORQUE L4 & 58 & -9.23 & 7.02 & 240 & -18.95 & 4.96 & 9.96 & $<0.001$ \\
\hline TORQUE L3 & 58 & -1.95 & 7.49 & 240 & -12.73 & 4.65 & 10.48 & $<0.001$ \\
\hline TORQUE L2 & 58 & 5.50 & 8.26 & 240 & -3.24 & 5.37 & 7.68 & $<0.001$ \\
\hline TORQUE L1 & 58 & 9.68 & 9.18 & 240 & -1.71 & 5.79 & 9.02 & $<0.001$ \\
\hline
\end{tabular}

ns not significant

torque on the central and lateral incisors was, respectively, roughly $7^{\circ}$ and $6^{\circ}$ more positive in the African sample. Analogously, the canines displayed roughly $7^{\circ}$ less negative torque in the African sample, and approximately $6^{\circ}$ less negative torque was measured at the premolars and first molars (Table 3) (Figs. 8 and 9).

\section{Comparison of tip and torque of African and Caucasian groups with values reported by Andrews}

Statistically significant differences with respect to values reported by Andrews were found in terms of the tip values measured in the upper jaw of both African and Caucasian subjects [10] (Tables 4 and 5). In the African sample, only the tip measured at the upper central incisors, canines and first premolars was comparable with values reported by Andrews (differences of $<1^{\circ}$ ) (Table 4). In the Caucasian subjects, all upper crowns had angulation values significantly different to those measured in Andrews' original sample of North American subjects. The greatest differences were seen at the molars and premolars, and in our Caucasian sample, only the second molars had a negative tip (Table 5). A similar discrepancy was found in the lower jaw (Table 4); in the African group, substantial differences were noted at the lower incisors, which presented negative tip, at the first and second premolars and in particular at the first and second molars, which both had considerably greater angulation values in our sample, the difference being as much as $10^{\circ}$ at the second molars. Likewise, in our Caucasian group, lower tip values were markedly different to those reported by Andrews, especially in the posterior
Table 7 Comparison of our Caucasian torque values with those measured by Andrews

\begin{tabular}{|c|c|c|c|c|c|c|c|c|}
\hline \multicolumn{4}{|c|}{ Caucasians-torque } & \multicolumn{3}{|c|}{ Andrews' values } & \multicolumn{2}{|c|}{ Comparison } \\
\hline & $n$ & Mean & $\begin{array}{l}\text { Standard } \\
\text { deviation }\end{array}$ & $n$ & Mean & $\begin{array}{l}\text { Standard } \\
\text { deviation }\end{array}$ & $\begin{array}{l}t \\
\text { test }\end{array}$ & $p$ level \\
\hline $\begin{array}{l}\text { TORQUE } \\
\text { U7 }\end{array}$ & 60 & -5.50 & 12.23 & 240 & -8.10 & 5.63 & 1.60 & ns \\
\hline $\begin{array}{l}\text { TORQUE } \\
\text { U6 }\end{array}$ & 60 & -6.26 & 10.24 & 240 & -11.53 & 3.91 & 3.92 & $<0.001$ \\
\hline $\begin{array}{l}\text { TORQUE } \\
\text { U5 }\end{array}$ & 60 & -3.54 & 6.42 & 240 & -8.78 & 4.13 & 6.02 & $<0.001$ \\
\hline $\begin{array}{l}\text { TORQUE } \\
\text { U4 }\end{array}$ & 60 & -5.35 & 5.64 & 240 & -8.47 & 4.02 & 4.04 & $<0.001$ \\
\hline $\begin{array}{l}\text { TORQUE } \\
\text { U3 }\end{array}$ & 60 & -3.35 & 7.15 & 240 & -7.25 & 4.21 & 4.05 & $<0.001$ \\
\hline $\begin{array}{l}\text { TORQUE } \\
\text { U2 }\end{array}$ & 60 & 6.23 & 6.31 & 240 & 4.42 & 4.38 & 2.10 & 0.040 \\
\hline $\begin{array}{l}\text { TORQUE } \\
\text { U1 }\end{array}$ & 60 & 7.41 & 6.19 & 240 & 6.11 & 3.97 & 1.54 & ns \\
\hline $\begin{array}{l}\text { TORQUE } \\
\text { L7 }\end{array}$ & 60 & -33.26 & 11.69 & 240 & -36.03 & 6.57 & 1.77 & ns \\
\hline $\begin{array}{l}\text { TORQUE } \\
\text { L6 }\end{array}$ & 60 & -29.24 & 9.29 & 240 & -30.67 & 5.90 & 1.14 & ns \\
\hline $\begin{array}{l}\text { TORQUE } \\
\text { L5 }\end{array}$ & 60 & -17.43 & 7.98 & 240 & -23.63 & 5.58 & 5.68 & $<0.001$ \\
\hline $\begin{array}{l}\text { TORQUE } \\
\text { L4 }\end{array}$ & 60 & -14.96 & 7.69 & 240 & -18.95 & 4.96 & 3.83 & $<0.001$ \\
\hline $\begin{array}{l}\text { TORQUE } \\
\text { L3 }\end{array}$ & 60 & -9.01 & 5.74 & 240 & -12.73 & 4.65 & 4.66 & $<0.001$ \\
\hline $\begin{array}{l}\text { TORQUE } \\
\text { L2 }\end{array}$ & 60 & -1.36 & 6.89 & 240 & -3.24 & 5.37 & 1.97 & ns \\
\hline $\begin{array}{l}\text { TORQUE } \\
\text { L1 }\end{array}$ & 60 & 2.19 & 7.11 & 240 & -1.71 & 5.79 & 3.93 & $<0.001$ \\
\hline
\end{tabular}

ns not significant. 
sectors, in which the crowns displayed a more positive tip (Table 5).

As regards the torque in the upper arcade, we found a greater positive tendency in the African subjects with respect to Andrews' measurements. This was true of all teeth except for the second molars, which had a more negative inclination in our sample (Table 6). The only upper teeth in which there were no statistically significant differences in the Caucasian group were the central incisors and second molars; the torque on the upper lateral incisors and first premolars was roughly $2-3^{\circ}$ lower, and this discrepancy reached $4-5^{\circ}$ at the canines, second premolars and first molars (Table 7). In the lower jaw, the torque values we measured in African subjects were in all cases more positive than those reported by Andrews. Differences were statistically significant in all cases, from a minimum of roughly $5^{\circ}$ at the second molar, up to approximately $12^{\circ}$ at the second premolar (Table 6). In the Caucasians we studied, the torque on the lower molars and lateral incisors was comparable to Andrews' measurements, while the torque we measured at the two premolars was less negative. In contrast to the other teeth, the central incisors displayed a positive torque (Table 7).

\section{Analysis of in-out values}

In both jaws of our African sample (Table 8), there is an observable tendency for the in-out values to increase progressively from the lateral incisor to the second molar. The same was true for the Caucasian subjects we measured (Table 8). However, a comparison of our

Table 8 Comparison of African and Caucasian in-out values

\begin{tabular}{llllllllll}
\hline \multicolumn{1}{c}{ Africans-in-out } & \multicolumn{3}{c}{ Caucasians-in-out } & \multicolumn{2}{c}{ Comparison } \\
\hline & $n$ & Mean & $\begin{array}{l}\text { Standard } \\
\text { deviation }\end{array}$ & $n$ & Mean & $\begin{array}{l}\text { Standard } \\
\text { deviation }\end{array}$ & t test & $p$ level \\
\hline U1 & 58 & 1.62 & .30 & 58 & 1.48 & .30 & 2.60 & 0.012 \\
U2 & 58 & 1.25 & .24 & 58 & 1.15 & .24 & 2.11 & 0.039 \\
U3 & 58 & 1.65 & .31 & 58 & 1.66 & .34 & -.30 & $\mathrm{~ns}$ \\
U4 & 58 & 1.89 & .33 & 58 & 1.61 & .24 & 5.20 & $<0.001$ \\
U5 & 58 & 1.85 & .29 & 58 & 1.66 & .29 & 3.60 & $<0.001$ \\
U6 & 58 & 2.29 & .40 & 58 & 2.01 & .47 & 3.35 & 0.001 \\
U7 & 58 & 2.47 & .56 & 58 & 2.75 & .62 & -2.51 & 0.015 \\
L1 & 58 & 1.18 & .21 & 58 & 1.01 & .32 & 3.42 & 0.001 \\
L2 & 57 & 1.16 & .19 & 58 & .93 & .32 & 4.65 & $<0.001$ \\
L3 & 58 & 1.36 & .28 & 58 & 1.38 & .27 & -.41 & $\mathrm{~ns}$ \\
L4 & 58 & 2.01 & .38 & 58 & 1.93 & .28 & 1.30 & $\mathrm{~ns}$ \\
L5 & 56 & 2.06 & .45 & 58 & 1.91 & .32 & 2.06 & 0.044 \\
L6 & 58 & 2.53 & .37 & 58 & 2.66 & .38 & -1.96 & $\mathrm{~ns}$ \\
L7 & 56 & 2.22 & .65 & 58 & 2.83 & .72 & -4.76 & $<0.001$ \\
\hline
\end{tabular}

ns not significant.
Table 9 Comparison of our African in-out values with those measured by Andrews

\begin{tabular}{|c|c|c|c|c|c|c|c|c|}
\hline \multicolumn{4}{|c|}{ Africans-in-out } & \multicolumn{3}{|c|}{ Andrews_-in out } & \multicolumn{2}{|c|}{ Comparison } \\
\hline & $n$ & Mean & $\begin{array}{l}\text { Standard } \\
\text { deviation }\end{array}$ & $n$ & Mean & $\begin{array}{l}\text { Standard } \\
\text { deviation }\end{array}$ & $t$ test & $p$ level \\
\hline$\overline{U 1}$ & 58 & 1.62 & .30 & 240 & 2.01 & .32 & -8.73 & $<0.001$ \\
\hline U2 & 58 & 1.25 & .24 & 240 & 1.84 & .30 & -15.82 & $<0.001$ \\
\hline U3 & 58 & 1.65 & .31 & 240 & 2.67 & .39 & -21.40 & $<0.001$ \\
\hline U4 & 58 & 1.89 & .33 & 240 & 2.54 & .35 & -13.36 & $<0.001$ \\
\hline U5 & 58 & 1.85 & .29 & 240 & 2.48 & .36 & -14.22 & $<0.001$ \\
\hline U6 & 58 & 2.29 & .40 & 240 & 2.88 & .40 & -10.17 & $<0.001$ \\
\hline U7 & 58 & 2.47 & .56 & 238 & 3.00 & .51 & -6.58 & $<0.001$ \\
\hline L1 & 58 & 1.18 & .21 & 240 & 1.59 & .27 & -12.61 & $<0.001$ \\
\hline L2 & 58 & 1.16 & .19 & 240 & 1.64 & .32 & -14.63 & $<0.001$ \\
\hline L3 & 58 & 1.36 & .28 & 240 & 2.37 & .40 & -22.57 & $<0.001$ \\
\hline$\llcorner 4$ & 58 & 2.01 & .38 & 240 & 2.72 & .43 & -12.52 & $<0.001$ \\
\hline L5 & 56 & 2.06 & .45 & 240 & 2.60 & .34 & -8.49 & $<0.001$ \\
\hline L6 & 58 & 2.53 & .37 & 240 & 3.02 & .40 & -9.00 & $<0.001$ \\
\hline L7 & 58 & 2.22 & .65 & 236 & 2.79 & .47 & -6.22 & $<0.001$ \\
\hline
\end{tabular}

ethnic groups revealed that the in-out values were greater in all teeth of the African upper jaw except for the second molars (Table 8). In the lower jaw, we found statistically significant differences at both sets of incisors and the second premolars, whose torque values were greater in the African group. In contrast, the second molar had a greater prominence, roughly $0.6 \mathrm{~mm}$

Table 10 Comparison of our Caucasian in-out values with those measured by Andrews

\begin{tabular}{|c|c|c|c|c|c|c|c|c|}
\hline \multicolumn{4}{|c|}{ Caucasians_-in-out } & \multicolumn{3}{|c|}{ Andrews-in-out } & \multicolumn{2}{|c|}{ Comparison } \\
\hline & $n$ & Mean & $\begin{array}{l}\text { Standard } \\
\text { deviation }\end{array}$ & $n$ & Mean & $\begin{array}{l}\text { Standard } \\
\text { deviation }\end{array}$ & $t$ test & $p$ level \\
\hline U1 & 60 & 1.48 & 0.30 & 240 & 2.01 & 0.32 & -11.88 & $<0.001$ \\
\hline U2 & 60 & 1.15 & 0.24 & 240 & 1.84 & 0.30 & -18.36 & $<0.001$ \\
\hline U3 & 60 & 1.66 & 0.34 & 240 & 2.67 & 0.39 & -19.75 & $<0.001$ \\
\hline U4 & 60 & 1.61 & 0.24 & 240 & 2.54 & 0.35 & -24.19 & $<0.001$ \\
\hline U5 & 60 & 1.66 & 0.29 & 240 & 2.48 & 0.36 & -18.53 & $<0.001$ \\
\hline U6 & 60 & 2.01 & 0.47 & 240 & 2.88 & 0.40 & -12.86 & $<0.001$ \\
\hline U7 & 60 & 2.75 & 0.62 & 238 & 3.00 & 0.51 & -2.85 & 0.006 \\
\hline L1 & 60 & 1.01 & 0.32 & 240 & 1.59 & 0.27 & -12.97 & $<0.001$ \\
\hline L2 & 60 & 0.93 & 0.32 & 240 & 1.64 & 0.32 & -14.98 & $<0.001$ \\
\hline L3 & 60 & 1.38 & 0.27 & 240 & 2.37 & 0.40 & -22.91 & $<0.001$ \\
\hline L4 & 60 & 1.93 & 0.28 & 240 & 2.72 & 0.43 & -17.36 & $<0.001$ \\
\hline L5 & 60 & 1.91 & 0.32 & 240 & 2.60 & 0.34 & -14.55 & $<0.001$ \\
\hline L6 & 60 & 2.66 & 0.38 & 240 & 3.02 & 0.40 & -6.37 & $<0.001$ \\
\hline L7 & 60 & 2.83 & 0.72 & 236 & 2.79 & 0.47 & 0.37 & ns \\
\hline
\end{tabular}




\section{a AFRICANS a CAUCASIAN \\ a ANDREWS}

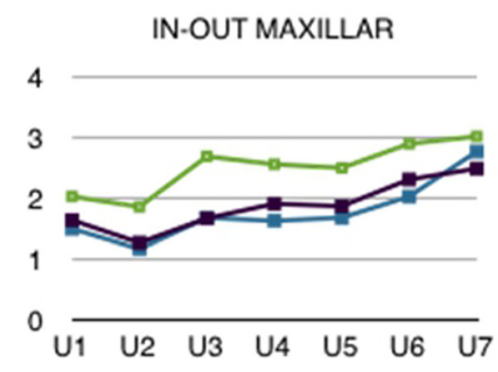

a AFRICANS a CAUCASIAN

a ANDREWS

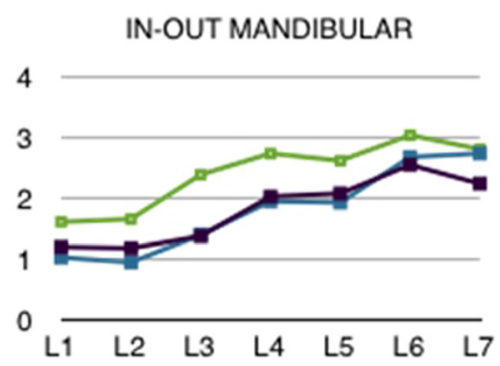

Fig. 10 A comparison of in-out values we measured with those of Andrews

(statistically significant), in our Italian Caucasian sample (Table 8).

Both of our samples were significantly different from that of Andrews in terms of in-out. In both of our samples, the mean prominence was greater than in Andrews' North American group at all teeth (Tables 9 and 10).

\section{Discussion}

On the whole, our findings from this part of the study are in line with those previously reported in the literature $[2-5,8]$, namely that ethnic background appears to play a significant role in determining the angulation and inclination of the teeth in both arcades. In certain circumstances, these ethnic differences can be great enough (i.e. greater than $3^{\circ}$ ) to take on clinical relevance.

Indeed, although our sample size was relatively small, if our measurements were taken as reference values, orthodontic bracket prescription would need to be altered or bends made in the wire to obtain optimal finishing in the Mozambican population.

When comparing the values we measured in our Italian sample with those reported by Andrews, it became clear that on the whole, their teeth had a more positive tip (i.e. a greater mesiodistal angulation). Similarly, torque values were larger on the whole in our sample. Hence, the results of this part of the study also agree with the literature, showing that individuals of the same race have different tip and torque values, depending on their ethnic background. Indeed, a similar picture was seen in two different Japanese [2] and Indian [4] samples, as well as Andrews' North American Caucasians.

As regards the in-out measurements, those taken on our sample showed that the lateral incisors had the smallest values, whereas the molars were the most prominent. We also revealed a similar trend in both samples for the in-out values to progressively increase in an anteroposterior direction from the central incisor to the second molar. The African sample generally (incisors, premolars and first molars) presented greater in- out values than the Caucasian group in the upper jaw. In the lower jaw, the vestibular prominence of the tooth crowns was essentially similar in African and Caucasian subjects. With respect to Andrews' values, however, we did notice a difference, as we revealed a tendency for the in-out values to increase towards the posterior sectors, where, according to the American author, there is none. Moreover, many of the values in our sample were smaller than those measured by Andrews, which may suggest that the coronal prominence in an anteroposterior direction is lower in Africans and Italian Caucasians than in North American Caucasians (Fig. 10).

Furthermore, the standard deviation values that emerged in our statistical analysis of the two samples were significant in some cases, thereby demonstrating that there is a considerable dispersion around the mean measurements for each tooth, especially in terms of torque. This finding, in agreement with previous studies [1-4, 6, 11-13], must be interpreted as a consequence of the biological variation in the inclination and angulation of the teeth, the variation in profile of the clinical crown, and variations in the inclination of the occlusal plane.

\section{Conclusion}

- The measurement system used on our sample is repeatable.

- There is great dispersion around the mean values measured for each tooth (especially torque).

- Race and ethnicity greatly influence tip, torque and in-out values.

- Caucasians have more positive tip values and Africans, more positive torque values, with greater proclination of the incisors.

- In-out values were slightly greater in the African sample than in the Caucasian group, especially in the upper arch.

- Both Caucasian and African groups differ from Andrews' sample in tip, torque and in-out values. 


\section{Competing interests}

The authors declare that they have no competing interests.

\section{Authors' contributions}

$\mathrm{LL}$ designed the research protocol, AP carried out the measurements, AA drafted the manuscript, ML carried out the data processing and statistical analysis, GS supervised the research. All authors read and approved the final manuscript.

Received: 21 March 2015 Accepted: 30 April 2015

Published online: 26 May 2015

\section{References}

1. Sebata E. An orthodontic study of teeth and dental arch form on the Japanese normal occlusions. The Shikwa Gakuho. 1980;80:945-69.

2. Watanabe K, Koga M, Yatabe K, Motegi E, Isshiki Y. A morphometric study on setup models of Japanese malocclusions. The Shikwa Gakuho. 1996;96:209-22.

3. Currim S, Wadkar PV. Objective assessment of occlusal and coronal characteristics of untreated normals: a measurement study. Am J Orthod Dentofacial Orthop. 2004;125(5):582-8.

4. Doodamani GM, Khala AS, Manohar M, Umashankar. Assessment of crown angulations, crown inclinations, and tooth size discrepancies in a South Indian population. Contemp Clin Dent. 2011;2(3):176-81.

5. Ferrario VF, Sforza C, Colombo A, Ciusa V, Serrao G. Three-dimensional inclination of the dental axes in healthy permanent dentitions-a cross sectional study in a normal population. Angle Orthod. 2001;71(4):257-64.

6. Lombardo L, Fattori L, Mirabella D, Molinari C, Siciliani G. Dental and alveolar arch forms in a Caucasian population compared with commercially available archwires. Int Orthod. 2013;115:1-33.

7. Balut N, Klapper L, Sandrik J, Bowman D. Variations in bracket placement in the preadjusted orthodontic appliance. Am J Orthod Dentofacial Orthop. 1992;102:62-7.

8. Tong H, Kwon D, Shi J, Sakai N, Enciso R, Sameshima GT. Mesiodistal angulation and faciolingual inclination of each whole tooth in 3dimensional space in patients with near-normal occlusion. Am J Orthod Dentofacial Orthop. 2012;141(5):604-17.

9. Huanca Ghislanzoni LT, Lineberger M, Cevidanes LH, Mapelli A, Sforza C, McNamara Jr JA. Evaluation of tip and torque on virtual study models: a validation study. Prog Orthod. 2013;14:19.

10. Caputi S, Varvara G. Dimensional accuracy of resultant casts made by a monophase, one-step and two-step, and a novel two-step putty/light-body impression technique: an in vitro study. J Prosthet Dent. 2008;99(4):274-81.

11. Andrews LF 1993: Straight wire. Masson Spa Milano

12. Vardimon $A D$, Lambertz W. Statistical evaluation of torque angles in reference to straight-wire appliance (SWA) theories. Am J Orthod. 1986;89:56-66.

13. Uğur T, Yukay F. Normal faciolingual inclinations of tooth crowns compared with treatment groups of standard and pretorqued brackets. Am J Orthod Dentofacial Orthop. 1997;112(1):50-7.

\section{Submit your manuscript to a SpringerOpen ${ }^{\odot}$ journal and benefit from:}

- Convenient online submission

- Rigorous peer review

- Immediate publication on acceptance

- Open access: articles freely available online

- High visibility within the field

- Retaining the copyright to your article

Submit your next manuscript at $>$ springeropen.com 